\title{
Criterios filosófico-jurídicos para administrar justicia de Alonso de la Veracruz. Formulación histórica y actualidad
}

JESÚS ANTONIO DE LA TORRE RANGEL

Departamento de Historia/UAA

Para Amilton Bueno de Carvalho.

"Los dedicados a seguir los asuntos en el foro deben preferir la caridad del prójimo al negocio secular..." San Isidoro de Sevilla, Sentencias. NTRODUCCIÓN

Alonso de la Veracruz (1507-1584) es uno de los autores más importantes de nuestra tradición teórica hispanoamericana de los derechos humanos. Los criterios filosófico-jurídicos del agustino impulsan y enriquecen esta concepción de los derechos humanos, la cual, a partir del reconocimiento de la dignidad humana, defiende los derechos de todos; y partiendo también de reconocer la opresión histórica de los pobres -en concreto de los empobrecidos indios-, rescata, ante todo, sus derechos en cuanto que oprimidos. Se trata de una visión de los derechos desde el pobre.

Fray Alonso de la Veracruz constituye una de las figuras intelectuales más destacadas de la Nueva España. Siendo catedrático de Artes en la Universidad de Salamanca, Alonso Gutiérrez -que era su nombre antes de ingresar a la Orden de San Agustín-, fue convencido de venir a estas tierras en su carácter de profesor. Haciendo una apretada síntesis de las tareas que Alonso de la Veracruz 
llevó a cabo en México, podemos decir que fue un infatigable misionero; fue fundador de colegios, bibliotecas y centros de enseñanza para los religiosos de su Orden y para los indios; fue el primer profesor de Filosofía en el Continente Americano precisamente en el Colegio de Altos Estudios de Tiripetío (1540), y primer catedrático de Teología Tomista y Sagrada Escritura al fundarse la Universidad de México (1553); en su Orden fue maestro de novicios y varias veces provincial; escribió varios libros de Filosofía y Derecho; y es, en la teoría y en la práctica, defensor de los derechos de los indios y de las propias congregaciones religiosas.

Aquí pretendemos resaltar solamente algunos criterios sustentados por Veracruz con relación a la esencia del Derecho, y cuyos razonamientos se ligan en concreto con la impartición de justicia. Estas reflexiones del ilustre profesor de la Universidad de México, están plasmadas en la Cuestión $\mathrm{X}$ de su relección o tratado De decimis (Sobre los diezmos).

De paso, el análisis que hagamos de esa décima duda nos permitirá conocer, sintéticamente, la argumentación del filósofo novohispano en contra de la supuesta obligación de los indios de pagar diezmos. Y los criterios filosófico-jurídicos para administrar justicia, sustentados por el agustino, nos llevan a reflexionar sobre una práctica alternativa del Derecho que se da en la actualidad.

Nuestras investigaciones jurídicas han tenido como interés central la temática de la Filosofía del Derecho, moviéndose en dos direcciones: la Historia del Derecho y la sistematización teórica de la práctica jurídica que ha sido denominada como Uso Alternativo del Derecho. En dos obras hemos logrado integrar los tres temas mencionados: El Uso Alternativo del Derecho por Bartolomé de las Casas $^{1}$ y Alonso de la Veracruz: Amparo de los Indios. ${ }^{2}$ Decimos lo

1. Ed. Universidad Autónoma de Aguascalientes. Aguascalientes, 1981. (Segunda edición en 1986).

2. De próxima aparición.

$114 \square C$ A 
anterior porque este trabajo refleja esa labor de investigación cuyo objeto primordial es filosófico, pero al mismo tiempo se hace Historia del Derecho y se proyecta a la actualidad en una de las vertientes del Uso Alternativo del Derecho.

\section{ConTEXTO HISTÓRICO PARTICULAR DE DE DECIMIS}

El brillante y muy cumplido profesor de la Universidad de México, fray Alonso de la Veracruz, preparó su relección correspondiente al curso de 1554-1555 sobre los diezmos, De decimis, ${ }^{3}$ en la cual expresaba su opinión en el sentido de que los indios no tenían la obligación de pagarlos. Esta relectio, sin embargo, no fue pronunciada, pues el arzobispo de México, el dominico Alonso de Montúfar "se opuso e incluso la secuestró". ${ }^{4}$

Cuando años después se intentó publicar De decimis, Alonso de la Veracruz en la parte en que dedica el texto al rey Felipe II, escribe:

Lo que yo he reflexionado, desarrollado y perfeccionado quise, proponerlo a otros como guía para formar opinión dando a conocer este tratado, en una serie de exposiciones públicas. Es costumbre que los catedráticos de estudios den cada año un simposio sobre los tratados que han explicado en clase. Yo como soy el titular de ciencias sagradas quise atender ambas obligaciones: mi deber para con la universidad y hacer una clara exposición a todos sobre asunto tan complicado y controversial. Mas, por una cosa u por otra, no pude hacer públicas estas ponencias, y me decidí a mandarlas a la imprenta para así dar a conocer su contenido. ${ }^{5}$

3. Prometeo Cerezo de Diego. Alonso de la Veracruz y el Derecho de Gentes. Ed. Porrúa. México, 1985, p. 55.

4. Roberto Jaramillo Escutia, en la Introducción a la obra de Alonso de la Veracruz Sobre los Diezmos, texto íntegro en castellano de De decimis, Trad. Rubén Pérez Azuela, 0.S.A. Ed. Organización de Agustinos de Latinoamérica (OALA). México, 1994, p. 12.

5. Veracruz. Sobre los Diezmos. Ob. cit., Parg. 7, p. 18. 
Fray Alonso de Montúfar había tomado posesión del Arzobispado de México, como sucesor de Zumárraga, el 24 de junio de $1554,{ }^{6}$ después de algunos años de haber estado la sede vacante. Era ya de avanzada edad, pues había nacido en Loja, Andalucía, en 1489. Dice el P. Cuevas que "se nota que a este prelado le dominó cierta acrimonia senil; esto por un lado, y por otro, una partida de clérigos seculares, de lo peorcito de España, habíase colado, no sólo a esta nueva tierra y cristiandad, sino al palacio mismo del arzobispo y quedó el pobre anciano muy impresionado y como dominado de las amarguras contra los religiosos y en particular contra los franciscanos". Montúfar va a tener varios puntos de divergencia con los religiosos, derivándose de algunos de ellos conflictos serios; por mencionar dos: uno con el lego franciscano y gran educador Pedro de Gante, por la erección que había hecho éste de las cuatro iglesias en los cuatro barrios indígenas que rodeaban al México de los españoles; ${ }^{8}$ y otro, sobre los diezmos con el agustino de la Veracruz.

Los diezmos habían sido concedidos por el Papa a la Corona española en virtud de una de las bulas que constituyen el Regio Patronato Indiano. En efecto, el papa Alejandro VI, por medio de la bula Eximiae Devotionis, de 16 de noviembre de 1501, concedió a los reyes españoles el disfrute de los diezmos que entonces se cobraban o en lo sucesivo se cobrasen. La Corona daba parte de esos diezmos a los obispos para el sostén de las iglesias. Por iglesias, dice Cuevas, "se entendían los obispos, catedrales y clero secular." Y agrega: "Los religiosos vivían de limosna, no obligatoria para los donantes, que eran indios en su inmensa mayoría".

6. Cfr. Mariano Cuevas. Historia de la Iglesia en México. Ed. Cervantes. México, 1942. Tomo II, p. 71.

7. Mariano Cuevas. Historia de la Nación Mexicana. Ed. Porrúa. México, 1967, p. 226.

8. Cfr. Ezequiel A. Chávez. Fll Primero de los Grandes Educadores de la América Fray Pedro de Gante. Imprenta Mundial. México, 1934, ps. 80-83.

9. Cuevas. Historia de la Nación Mexicana. Ob. cit., p. 227. 
Nos dice el jesuita historiador:

Montúfar, probablemente de muy mala gana, quería dar parroquias, empleos y que comer a tanto clérigo secular hambriento como venía en cada barcada a la Veracruz. Lo más natural, hablando en abstracto sería mandarlos a tantísima tierra, como aún quedaba, sin cultivo espiritual, para que, imitando a los religiosos, con mucha abnegación y sacrificio, anduviesen leguas y leguas, aprendiesen lenguas indígenas y viviesen de limosna. Pero la mayor parte estaba muy lejos de todo esto; querían beneficios, como los que habían tenido o, por lo menos, envidiado en España y, por supuesto, había de ser a base de diezmos. El indio no podía dar diezmos y, en muchos casos, tratándose de algunos clérigos, tampoco quería darlos. ${ }^{10}$

Lo anterior explica los conflictos del arzobispo con los religiosos, principalmente con los franciscanos; y explica, también, el hecho de que impidiera la repetición de cátedra de Veracruz sobre los diezmos, y tratara de impedir la publicación de este tratado y cualquiera otra obra del agustino, por medio de una carta del presbítero Gonzalo de Alarcón al rey Felipe II. ${ }^{11}$ Pues como dice Basalenque, lo que Veracruz escribe acerca de los diezmos "era doctrina muy odiosa a los señores Obispos, mas como su autoridad era tanta no le podían contradecir", ${ }^{12}$ por eso trataban de callarlo.

El tratado todo sobre los diezmos, en su temática amplia y en su tono, se entiende si se tiene en cuenta la descripción de la Iglesia mexicana que nos ha ofrecido el P. Cuevas. De decimis mismo, nos da a conocer indirectamente y en algunos lugares directamente, qué vicios y virtudes caracterizaban a la Iglesia novohispana de la época.

El tratado Sobre los Diezmos contiene veintiséis dudas o cuestiones. En ellas se hace un análisis profundo, en toda la amplitud

10. Idem Supra.

11. Cfr. Cerezo. Ob. cit., p. 62.

12. Diego Basalenque. Historia de la Provincia de San Nicolás de Tolentino de Michoacán Del Orden de N.P.S. Agustín. Ed. Jus. México, 1963, p. 92. 
de la materia. No todo el texto aborda de manera directa la cuestión de los indios y el pago de los diezmos, sino que se tocan muchas otras materias relacionadas con esa obligación eclesiástica; esto, aunque nunca el autor deja que se pierda de vista el objeto tratado, siempre cuida que se encamine a la cuestión central que nos hemos referido: resolver si los indios tienen obligación de pagar diezmos y, consecuentemente, si se les puede exigir conforme a Derecho.

Vamos, entonces, al análisis de la décima duda del tan polémico tratado del fraile agustino.

\section{La Cuestión X de DE DECIMIS: CRITERIOS PARA EL MEJOR ENTENDIMIENTO DE LA ESENCIA DEL DERECHO}

El desarrollo de la Cuestión X o décima duda del tratado Sobre los Diezmos de fray Alonso de la Veracruz, constituye un capítulo muy jurídico, que propone reflexiones jusfilosóficas de enorme importancia, pues toca cuestiones relacionadas con lo que el Derecho es en sentido más propio, sobre su esencia misma.

Son dos las argumentaciones que nos interesa resaltar. Una primera es sobre la cuestión de la forma frente al contenido del Derecho, la formalidad ante la materia, discutiéndose, en el fondo, en donde radica la prioridad del Derecho, en una o en otra. La segunda de algún modo deriva de la primera, va directamente al terreno judicial, y trata acerca de si los jueces deben dictar sentencia basados sólo en lo "alegado y probado" en el juicio (forma); esto independientemente de que los propios jueces, fuera de lo "alegado y probado", conozcan otras cuestiones que contradicen eso que se alegó y probó, y que tomando en cuenta ese conocimiento su sentencia sería contraria precisamente a lo que apoya eso que aparece como "alegado y probado" (materia, contenido, realidad).

Esta temática surge de la pregunta clave que se propone como Cuestión X. 
Se pregunta en décimo lugar, si cesando la razón de la ley, cesa también su obligación.

Cuestión décima. Antes de seguir adelante es conveniente investigar si cesando la razón y causa de la ley, cesa también la obligación. ${ }^{13}$

Enseguida Veracruz, siguiendo el método escolástico, propone los argumentos que contradicen lo que él sostendrá más adelante -que cesando la razón de la ley cesa su obligación- argumentos que priorizan la forma sobre la materia, proponiéndose como ejemplos la solemnidad de los testamentos sobre la voluntad del testador y las formalidades procedimentales como base de las sentencias de los jueces, sobre la verdad real conocida por esos propios jueces. Dejemos esto así, por ahora, como el jusfilósofo lo deja en De decimis y sigamos su texto. Después volveremos, como lo hace Veracruz, a hacernos cargo de estas argumentaciones.

Enseguida el autor hace algunas advertencias, hace notar otras cosas y distingue lo que es menester distinguir, antes de pasar a las conclusiones.

Demos a conocer las notas previas de Veracruz antes de sus conclusiones.

Para la solución de la cuestión hay que advertir, en primer lugar, que la causa o razón de la ley puede cesar de dos maneras: una, en el caso particular de una persona, y otra respecto a todos los casos. Por ejemplo, si hubiese una ley por la cual ninguno pueda llevar armas en la noche y quien las lleve las pierde, y la causa de la ley es por los pleitos y homicidios a que ello da lugar, pero hay un hombre pacífico en la república, del cual nada se teme, el cual lleva un arma. Para él cesa la razón de la ley pero no para los demás. Y cuando la razón de la ley cesara para todos, en el supuesto de que estuviese en vigor, si para nadie existiese peligro, entonces cesaría la ley.

Hay que notar, en segundo lugar, que la causa de la ley cesa en particular de dos modos o en cuanto a la intención principal de la ley y no a lo accesorio, o en cuanto a lo principal junto con lo accesorio, como si la ley sobre el pago de diezmos fuese impuesta para la sustentación de los ministros y como reconocimiento de la potencia divina y del dominio universal; en este

13. Veracruz. Sobre los Diezmos. Ob. cit., Pargs. 330 y 331, p. 117. 
caso puede cesar la causa o razón de la ley, en cuanto a una cosa y permanecer en cuanto a otra.

Hay que notar en tercer lugar, que cesando la causa, cesa la obligación de la ley: puede ser con escándalo de otros que ven que no se guarda la ley, o sin escándalo. Por ejemplo si se ha dado una ley de ayuno para la mortificación de la carne, alguien tiene la carne sujeta al espíritu y cena en secreto, sin que esto de hecho produzca escándalo en nadie, o por el contrario puede cenar con escándalo de otros.

Lo cuarto y último que se debe notar es que la ley de los diezmos nació por diversa razón de la ley, diversa o por lo menos una y otra fueron por la misma razón de la ley, por cuanto pertenece a la ley natural, es para el sustento de los ministros espirituales sin cuota determinada. ${ }^{14}$

Veracruz, enseguida, establece nueve conclusiones. Las cuatro primeras van directamente a responder a la cuestión planteada de manera general y abstracta, esto es, contestan a la duda de si cesando la razón de la ley, cesa también su obligación. Las cinco conclusiones restantes son aplicación, concretización, a la materia de los diezmos de las respuestas contenidas en las cuatros primeras conclusiones. Las primeras cuatro conclusiones tienen una enorme proyección, pues el criterio adoptado permite aplicaciones diversas a las cuestiones relativas a la juridicidad en general; de hecho, las cinco conclusiones que versan directamente sobre la materia de los diezmos, constituyen derivaciones, proyecciones, de las cuatro primeras conclusiones.

Vamos a transcribir unas y otras. Las primeras se complementarán con las argumentaciones finales de Veracruz. Las del segundo grupo ahí quedarán dando fuerza a la defensa de los derechos de los indios que hace el agustino.

Primera conclusión. Cesando la razón y causa de la ley humana y universal, cesa también la obligación de la misma ley universalmente. Se prueba, primero: para que una ley sea obligatoria se requiere que sea justa, útil y dada para el bien. Como cesando la causa de la ley universalmente, ya no es

14. Idem Supra, Pargs. 336 a 339, ps. 118 y 119. 
útil ni para el bien común. Luego esa misma ley ya no tiene fuerza obligatoria... ${ }^{15}$

Veracruz sostiene que la razón y el fin de la ley "no sólo son el alma de la ley, sino la ley misma". ${ }^{16}$

Segunda conclusión. Cuando la razón de la ley cesa en particular, cesa también en particular la obligación de la ley, siempre que se evite el escándalo. Se prueba: si cesa la ley en particular en razón de esto, se da también universalmente con relación a todos. Como cuando la razón de la ley cesa universalmente, también cesa universalmente la obligación. Luego, también si es en particular, cesará en particular. ${ }^{17}$

Tercera conclusión. Cuando la ley se da por algo principal y otra cosa más accesoria, si cesa en cuanto a lo principal, lo menos accesorio se puede suplir de otra manera, cesa igualmente la obligación de la ley. Así por ejemplo si la ley sobre los peajes fue dada principalmente para la construcción de los puentes y la conservación de los caminos, y secundariamente para contribuir en algo a la sustentación de los reyes que exigen tales peajes, si se puede suplir lo segundo de otra manera, es decir, que con otros tributos se dé lo que es suficiente para el sustento, cesa la obligación de la ley. ${ }^{18}$

Cuarta conclusión. Si hubiese alguna ley dada por algo accesorio y menos importante, y por algo principal e importantísimo, por el hecho de que cese la razón relacionado con lo menos importante, no cesa la obligación de la ley..$^{19}$

Planteadas las respuestas al revés, "donde permanece la razón y el fin de la ley, debe permanecer la obligación de la misma". ${ }^{20}$

Éstas son, entonces, las conclusiones generales y en abstracto a la cuestión planteada; para Veracruz cesando la razón de la ley, cesa también su obligación, pues esa razón que constituye el fin de la ley, es la ley misma.

15. Idem Supra, Parg. 341, ps. 119 y 120.

16. Ibidem.

17. Idem Supra, Parg. 345, p. 121.

18. Idem Supra, Parg. 347, p. 121.

19. Idem Supra, Parg. 350, p. 122.

20. Ibidem. 
Pasamos ahora a las conclusiones que constituyen proyección de las anteriores y que se refieren a los diezmos.

Quinta conclusión. Por lo que se refiere a la ley natural, la obligación del pago de los diezmos para el sustento del ministro cesa también si no hay ministro, y cesa igualmente si se provee de lo necesario al ministro de otra manera. $^{21}$

La razón de la ley de los diezmos es el sustento del ministro; si cesa esa razón, o porque no hay ministro o porque hay sustento, cesa también la obligación del diezmo.

A continuación el misionero jurista establece esos corolarios con relación a la supuesta obligación de los indios de pagar diezmos.

De esta quinta conclusión se infiere que los indígenas del Nuevo Mundo, en cuanto a los diezmos que se deben a los ministros por derecho natural, no están obligados donde no hay quien los administre espiritualmente, e injustamente se les exigiría. No se llama administración el hacerlo una vez en la vida, ni siquiera una vez cada año, sino que para que se deba el alimento la administración ha de ser cotidiana, de otra manera sería suficiente la sustentación por el tiempo que se administra. Y ni el obispo, ni los canónigos, ni algún otro, en razón de la ley natural, pueden exigir el diezmo de aquéllos a quienes no dan nada. Pues donde nada se da, nada se recibe.

Por la misma razón se sigue también, que donde hay ministro y los neófitos del Nuevo Mundo le proveen de lo necesario para el honesto alimento y vestido, no están obligados además a los diezmos por ley natural: porque la razón para la obligación de la ley es el sustentar al ministro. Como el ministro ya está provisto, como suponemos. Luego no están obligados a otro diezmo o a otro porcentaje. ${ }^{22}$

Sexta conclusión. La obligación de la antigua ley divina de pagar diezmos cesó absolutamente, de modo que actualmente no tiene ningún valor. Es claro porque la razón de la ley se refería a un precepto judicial, porque los levitas no tenían territorio y no pertenecían a ninguna otra tribu. Pero ahora ni hay levitas que pertenezcan a una tribu particular, ni hay quienes no tengan otros recursos para vivir. Y como esa antigua ley cesó totalmente en cuanto a lo judicial y en cuanto a lo ceremorial, como se ha probado anteriormente, se sigue también que la obligación de esa ley se ha perdido.

21. Idem Supra, Parg. 351, p. 122.

22. Idem Supra, Pargs. 354 y 355, p. 123. 
Séptima conclusión. Donde no hay ministro, ni cuidado de los pobres, ni provisión para la fábrica y culto divino cesa la obligación de la ley humana para pagar los diezmos. Se prueba; la ley humana que dispone los diezmos, tiene como fin y causa el sostenimiento del ministro y la provisión para los pobres y la fábrica, porque cierta porción de tales diezmos son para esto, como antes se probó. Luego estas cosas no existen, cesa también la obligación de la ley, como el obvio por lo dicho antes. Pues el papa al mandar a los fieles que den los diezmos, no pretende otra cosa más que lo dicho. Por tanto, faltando esto, cesa también la obligación de pagar el diezmo. ${ }^{23}$

\section{Más adelante, en el parágrafo 358 Veracruz expresa un princi-} pio de la más pura tradición jusnaturalista: "una ley injusta no obliga en el foro de la conciencia". ${ }^{24}$

Octava conclusión. Donde los neófitos proveén a quienes los administran en lo espiritual, a los pobres, y a la fábrica y ornato necesario del templo, no están obligados a la ley del diezmo por derecho positivo y humano. ${ }^{25}$

Novena conclusión. Aún cuando la ley de pagar los diezmos en cuanto a la cuota fuese dado no sólo por las cosas dichas sino también para reconocer el dominio divino, igualmente cesando lo primero que es lo principal, la obligación no permanece. Es obvio por aquellas cosas que hice notar al principio de la cuestión: que cuando cesa la razón de la ley, cesa también la obligación, y en esas circunstancias al cesar la razón de la ley, cesa también la obligación. Como la razón de la ley cesa en cuanto se proveé para el ministro, los pobres, la fábrica de la iglesia, etc. Luego, por este motivo cesa la razón. Como los diezmos se exigen por esta razón. Luego, cesa la obligación. Se confirma. Si permaneciera la obligación, sería porque es conveniente que la creatura reconozca que Dios es su rey y señor. Como para este reconocimiento no es necesario el diezmo, porque puede hacerlo mediante las oblaciones y primicias, y con otras cosas, como realmente lo hacen los cristianos en muchas otras cosas por las cuales se ve claramente "que Dios es el Señor de los Señores". Luego, de ninguna manera permanece la obligación de dar los diezmos, una vez que se ha atendido ya al ministro y a los otros objetivos. ${ }^{26}$

23. Idem Supra, Pargs. 356 y 357, ps. 123 y 124.

24. Idem Supra, p. 124.

25. Idem Supra, Parg. 360, p. 124.

26. Idem Supra, Pargs. 364 y 365, p. 125. 


\section{RAZÓN Y CAUSA DE LA LEY: LOS CRITERIOS \\ PARA ADMINISTRAR JUSTICIA}

Después de las conclusiones, Veracruz pasa luego a ocuparse de los argumentos que en ciertos casos podrían contradecir lo que ha establecido en ellas en el sentido de que cesando la razón de la ley, cesa la obligación de la misma.

Se ocupa primero del argumento que sostiene que si no se dan las formalidades del testamento, éste es inválido, no importando que se contradiga la voluntad del testador, y pese a que se reconozca que las formas son para la seguridad de los actos jurídicos, tratándose de evitar con ellos fraudes o engaños.

Veamos que dice el jurista novohispano:

Por estas cosas y otras muchas los autores citados y otros varones graves, en otro tiempo maestros nuestros, sostuvieron esta opinión: tal testamento, por derecho humano, no da derecho a recibir la herencia, y en el foro de la conciencia, a suceder a aquél que murió intestado. Los que siguen la opinión de que como quiera que sea el argumento prueba, dice que en tal caso, aunque cese la razón de la ley, a saber, que no intervenga fraude o engaño, no por eso cesa la obligación de la misma.

Sin embargo, nosotros sostenemos la sentencia contraria, la cual defendimos hace tiempo en Salamanca en público y frente a un grupo de doctísimos varones, a saber, en el caso concreto del argumento, cesando la razón de la ley, también cesa la obligación y queda dentro de la ley natural y cómo por derecho natural puedo uno donar sus bienes y transferir el dominio a otro, así como también puede instituir heredero, aunque no se observen las solemnidades del derecho humano. ${ }^{27}$

La solución de Veracruz reafirma que para él, la esencia de lo jurídico está en su contenido, en su materia, y no en la forma. La forma prescrita por la ley tiene una razón de ser, que implica protección de la materia jurídica misma; si cesa esa razón de ser que tiene la forma, no tiene por que obligar ésta, si se deja a salvo el

27. Idem Supra, Pargs. 372 y 373, p. 127. 
contenido del derecho. Y es que la justicia no se da en las formas, sino en la materia, pues lo constituye la cosa o conducta debida a otro que es, en contrapartida, su derecho.

El otro asunto que parte de los argumentos es "cuestión grave" dice el propio Veracruz. Tiene que ver con la administración de justicia, con las sentencias de los jueces. La controversia es fuerte, y versa sobre si es lícito a los jueces, haciendo a un lado lo alegado y probado en el procedimiento, juzgar (decidir) basándose en la verdad que conocen.

Después de citar a varios autores, entre ellos a su maestro Domingo de Soto y a la máxima autoridad Santo Tomás de Aquino, nuestro jurista novohispano dice:

Todos estos autores y otros más afirman que el argumento es probatorio, es decir, que el juez está obligado a juzgar según lo alegado y probado, aunque le conste de la inocencia del reo, si por falsos testigos se ha probado que es culpable, debe obrar contra su conciencia por guardar la ley, pues no cesa la obligación de la ley. ${ }^{28}$

Santo Tomás de Aquino había respondido así a la cuestión:

RESPONDO: Debe decirse que, como se ha visto (a. I, y C. 6o, a. 2 y 6) el juzgar pertenece al juez, en cuanto que ejerce pública autoridad. y por esto debe informarse al juzgar no según lo que él conoce como persona particular, sino según lo que se le hace conocer como persona pública. Mas esto le es conocido en general y en particular. En general, por las leyes públicas ya divinas ya humanas, contra las cuales no debe admitir prueba alguna. Y en un negocio particular por instrumentos y testigos y otros legítimos documentos de esta índole, que debe seguir al juzgar, más bien que lo que sabe como persona privada. De lo cual, sin embargo, puede ayudarse para discutir con más cuidado las pruebas aducidas, a fin de poder investigar el defecto de ellas. Y si no las puede rechazar en derecho, debe según lo dicho seguirlas al juzgar. ${ }^{29}$

28. Idem Supra, Parg. 381, p. 130.

29. Santo Tomás de Aquino. Suma Teológica T. XI. La Prudencia, La Justicia y el Derecho. Versión del texto latino de Ismael Quiles. Club de Lectores. Buenos Aires, 1987, p. 234. 
Pese a toda la autoridad del Aquinate y de su maestro el segoviano De Soto, Alonso de la Veracruz sostiene lo contrario.

Sin embargo, nosotros negamos que en este caso el juez deba juzgar de acuerdo con lo alegado y probado, eliminando siempre el escándalo, más bien creemos que en este caso cesa la obligación de la ley. Y se prueba porque, dado que la prueba de los testigos se aduce para encontrar la verdad, si consta ya la verdad, no obliga la ley de juzgar, contra la justicia, Puesto que los juicios son instituidos en favor de la caridad y la justicia, no deben funcionar contra la caridad y la justicia. En este caso, ni el juez, si puede hacerlo sin escándalo, debería admitir la prueba de los testigos, cuando a él le conste con certeza la inocencia del reo, ni es necesario que se exhiban otras pruebas, sino que, de acuerdo con lo que le consta, debe absolver al reo en conciencia. ${ }^{30}$

Este parágrafo de la obra de Alonso de la Veracruz lo consideramos muy importante; primero, en cuanto a la concepción del Derecho en general; y segundo, porque abre enormes posibilidades para los jueces que de verdad quieren hacer justicia, cuando la ley de algún modo la está negando.

Por lo que ve a su concepción del Derecho, Veracruz va más allá de los criterios jurídicos de su formación salmantina de corte tomista -nótese que su argumento contradice a su maestro de Soto y al propio Santo Tomás-; Veracruz está recuperando la viejísima idea bíblica y profética del Derecho como mispat, en cuanto que lo entiende como hacerse cargo del desvalido, del desprotegido, pues está introduciendo en la administración de justicia, la noción de caridad además de la justicia: "Puesto que los juicios son instituidos en favor de la caridad y de la justicia, no deben funcionar contra la caridad y la justicia", dice textualmente.

Como Porfirio Miranda nos recuerda: "cuando en la historia humana se ideó la función de un juez... fue exclusivamente para ayudar a quienes por ser débiles no pueden defenderse; los otros no lo

30. Veracruz. Sobre los diezmos. Ob. cit., parg. 382, p. 130. 
necesitan" ${ }^{31}$ En el sentido de la caridad y la justicia en los juicios, es el más profundo sentido del Derecho en la tradición de los profetas de Israel. ${ }^{32}$

El segundo aspecto por el que nos parece muy importante el criterio de Veracruz es porque no considera que el juez sea un simple repetidor de la ley, sea esta justa o injusta, adecuada o inadecuada; el Derecho para Veracruz es la ley, pero es también más que la ley; si cesa la razón de la ley cesa también la obligatoriedad de ésta. Pero al cesar la obligatoriedad de la ley no quiere decir que el Derecho desaparece, que no hay más juridicidad, sino que el Derecho viene a integrarse con otros criterios que parten de principios de equidad y de justicia, y con los principios generales del Derecho; eso significa que el juez no dejará de juzgar, pero juzgará con base en esos criterios que hemos enunciado que deben basarse, según Veracruz, en la caridad y la justicia.

La labor de los jueces es una tarea de interpretación, que consiste en concretar la ley en cada caso; esta aplicación de la ley constituye, como dice Gadamer, la "complementación productiva" ${ }^{\prime 3}$ del Derecho.

Entendiendo también que el Derecho es más que la ley, el propio Gadamer nos ofrece estas reflexiones conectadas con la hermenéutica jurídica, y que empatan con los criterios filosóficos de Alonso de la Veracruz. Nos las presenta siguiendo a Aristóteles y precisamente distinguiendo entre la aplicación del saber técnico y la aplicación del saber jurídico en cuanto que saber moral.

31. Porfirio Miranda. Marx y la Biblia. Crítica a la Filosofía de la Opresión. México, 1971, p. 111.

32. Sobre este tema además de la obra citada arriba de Miranda, puede verse: José L. Sicre. Con los pobres de la Tierra. La justicia social en los profetas de Israel. Ed. Cristiandad. Madrid, 1984; y Jesús Antonio de la Torre Rangel Del Pensamiento Jurídico Contemporáneo. Aportaciones Críticas. Ed. Escuela Libre de Derecho y Miguel Angel Porrúa. México, 1992. En especial el capítulo IV.

33. Hans-Georg Gadamer. Verdad y Método I. Ed. Sígueme. Salamanca, 1996, p. 401. 
Por el contrario, el que 'aplica' el derecho se encuentra en una posición muy distinta. En una situación concreta se verá obligado seguramente a hacer concesiones respecto a la ley en sentido estricto, pero no porque no sea posible hacer las cosas mejor, sino porque de otro modo no sería justo. Haciendo concesiones frente a la ley no elimina aspectos de la justicia, sino que por el contrario, encuentra un derecho mejor. En su análisis de la epieikeia, la 'equidad' Aristóteles da a esto una expresión muy precisa: epieikeia es la corrección de la ley. Aristóteles muestra que toda ley se encuentra en una tensión necesaria respecto a la concreción del actuar, porque es general y no puede contener en sí la realidad práctica en toda su concreción...La ley es siempre deficiente, no porque lo sea en sí misma sino porque frente a la ordenación a la que se refieren las leyes, la realidad humana es siempre deficiente y no permite una aplicación simple de las mismas. ${ }^{34}$

\section{El Uso Alternativo del Derecho de los "Jueces Gauchos"}

En sociedades tan legalistas como las modernas, en las cuales el Estado legislador ha monopolizado la producción de lo jurídico como la ley, con las características de general, abstracta e impersonal, y donde doctrinariamente se entiende el Derecho como unívoco, aplicándose su sentido sólo a la normatividad estatal; digo, en nuestras sociedades, es muy difícil pensar en jueces que apliquen el criterio sustentado por el jurista novohispano, por esa reducción de lo jurídico a la ley.

Sin embargo, existe un movimiento de jueces que sí intentan una aplicación más justa de la ley, dándole interpretaciones que contradicen su sentido original injusto, cuando se necesita; me refiero a los llamados jueces gauchos del sur de Brasil, que buscan hacer uso alternativo del Derecho. ${ }^{35}$

34. Idem Supra, págs. 389 y 390.

35. Cfr. Amilton Bueno de Carvalho: Magistratura e Direito Alternativo. Ed. Acadêmica. São Paulo, 1992; "Sobre la jurisdicción criminal en Brasil, hoy. Carta abierta de un juez brasileño a un juez español", en Jueces para la Democracia NI 23. 3/1994. Madrid. De varios autores: Liçoes de Direito Alternativo 1 y 2, Ed. Acadêmica, São Paulo, 1992. Joaquín Herrera Flores y David Sánchez Rubio “Aproximación al dere- 
Entendemos por Uso Alternativo del Derecho -referido a nuestro medio latinoamericano-, las diversas acciones encaminadas a que toda la juridicidad (normas o leyes, derechos subjetivos y objetivización de la justicia) sea usada al servicio de los pobres como sujeto histórico, tanto en y ante las instancias judiciales y administrativas del Estado, como por ellos mismos en sus relaciones comunitarias creando y recreando la solidaridad.

Hasta hace poco tiempo estas nuevas tendencias en el uso del Derecho en América Latina, se ubicaban sólo en este movimiento dialéctico y de marcha conjunta dado entre comunidades de pobres y abogados con una nueva visión del Derecho. Sin embargo, en los últimos tiempos otro grupo se incorporó a estas nuevas tendencias del quehacer jurídico latinoamericano: los jueces. Aunque la locución de Uso Alternativo del Derecho había nacido en el seno de un grupo de jueces italianos, en América Latina había sido readaptado por abogados litigantes ligados a grupos populares, y la judicatura había sido hasta hace apenas unos años (1986) totalmente ajena a esta corriente e incluso contraria.

A fines de 1990 un grupo de jueces de Río Grande do Sul, ecuparon la primera plana de los diarios brasileños más importantes dando origen a un debate nacional sobre el modo en que los jueces deben usar la ley para administrar justicia. Esto se originó porque este grupo de jueces "gauchos" han fundado sus sentencias en criterios de justicia y no estrictamente en la ley, siendo esto totalmente contrario a las teorías jurídicas más aceptadas dentro de la concepción del monismo jurídico de la Modernidad. Todo esto, por cierto, con rasgadura de toga de los juristas tradicionales.

Uno de los principales promotores y exponentes de ese grupo de jueces, Amilton Bueno de Carvalho, ha manifestado como preocu-

cho alternativo en Iberoamérica", en Jueces para la Democracia No 20. 3/1993. Madrid. Jesús Antonio de la Torre Rangel. Sociología Jurídica y Uso Alternativo del Derecho. Ed. Instituto Cultural de Aguascalientes. Aguascalientes. (En prensa). 
pación el encontrar una teoría que justifique su práctica. ${ }^{36}$ Ciertamente Alonso de la Veracruz no les está proporcionando a los jueces una teoría completa y acabada que sustente el Uso Alternativo del Derecho desde la judicatura, pero sí está dando criterios valiosos que pueden ayudar a esos jueces a ir adquiriendo una formación teórica fuerte que soporte sus decisiones.

Criterios tales como ese principio de "cesando la razón y causa de la ley humana universal, cesa también la obligación de la misma ley universalmente", esto en cuanto que "para que una ley sea obligatoria se requiere que sea justa, útil y dada para el bien"; o las formalidades del derecho son para la seguridad, para evitar fraude y engaño, pero salvada esta razón, lo que debe prevalecer es la materia, la sustancia de lo jurídico, sobre la forma; "los juicios son instituidos en favor de la caridad y la justicia", no deben funcionar contra la caridad y la justicia; lo alegado y probado (forma) no debe prevalecer sobre la verdad (lo que es real), en el momento de emitir sentencia; etc. etc.

Estos criterios de Alonso de la Veracruz van en el sentido de lo que tan bien ha escrito Amilton Bueno sobre lo que es y no es el Derecho Alternativo. Para muestra:

Algunos dicen que el Derecho Alternativo se caracteriza por negar la ley. Y esto no corresponde a la realidad. La ley escrita es conquista de la humanidad y no se ve posibilidad de vida en sociedades sin normas (sean escritas o no). La alternatividad lucha para que surjan leyes efectivamente justas, comprometidas con los intereses de la mayoría de la población, o sea, realmente democráticas. Y busca instrumental interpretativo que siga la misma dirección. Lo que la alternatividad no reconoce es la identificación del derecho tan sólo con la ley, ni que sólo el Estado produzca derecho, lo que es diverso a negar a la ley. ${ }^{37}$

36. Cfr. Amilton Bueno de Carvalho."Actuación de los jueces alternativos gauchos en el proceso de postransición democrática ( 0 una nueva praxis en busca de una teoría)", en Portavoz No 40. Boletín del Instituto Latinoamericano de Servicios Legales Alternativos (ILSA). Bogotá, julio-octubre de 1994.

37. Amilton Bueno de Carvalho. Direito Alternativo na Jurisprudência. Ed. Acadêmica. São Paulo, 1993, p. 10. (El subrayado es nuestro). 
Los criterios filosófico-jurídicos de Alonso de la Veracruz demuestran el vigor de nuestra tradición teórica hispanoamericana de los derechos humanos, que sigue inspirando una rica reflexión y sigue invitando a la defensa de la dignidad humana, especialmente de la de aquéllos que sistemáticamente son agraviados, los más pobres. 
